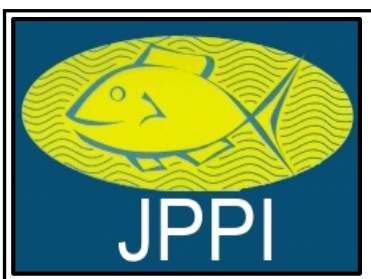

\author{
Tersedia online di: http://ejournal-balitbang.kkp.go.id/index.php/jppi \\ e-mail:jppi.puslitbangkan@gmail.com
}

JURNAL PENELITIANPERIKANANINDONESIA

Volume 23 Nomor 1 Maret 2017

p-ISSN: 0853-5884

e-ISSN: 2502-6542

Nomor Akreditasi: 653/AU3/P2MI-LIPI/07/2015

\title{
KARAKTERISTIK POPULASI UDANG JERBUNG (Penaeus merguiensis de Man, 1888) DI PERAIRAN CILACAP DAN SEKITARNYA
}

\section{POPULATION CHARACTERISTIC OF BANANA PRAWN (Penaeus merguiensis de Man, 1888) IN CILACAP AND ITS ADJACENT WATERS}

\author{
Ali Suman*1 dan Budi Iskandar Prisantoso ${ }^{2}$ \\ 'Balai Penelitian Perikanan Laut, Jl. Muara Baru Ujung, Komp. Pelabuhan Perikanan Nizam Zachman, Jakarta \\ Utara, 14430-Indonesia \\ ${ }^{2}$ Pusat Penelitian dan Pengembangan Perikanan, Jl. Pasir Putih II, Ancol Timur Jakarta Utara, 14430-Indonesia \\ Teregistrasi I tanggal: 20 Januari 2017; Diterima setelah perbaikan tanggal: 30 Maret 2017; \\ Disetujui terbit tanggal: 05 April 2017
}

\begin{abstract}
ABSTRAK
Tingginya permintaan pasar terhadap udang jerbung mengakibatkan aktivitas penangkapannya berlangsung secara terus-menerus sepanjang tahun sehingga mengancam kelestariannya. Penelitian karakteristik populasi merupakan salah satu dasar utama dalam merumuskan pengelolaan menuju pemanfaatannya secara lestari. Tujuan penelitian ini adalah untuk mengetahui karakteristik populasi udang jerbung di perairan Cilacap dan sekitarnya. Penelitian dilakukan dari bulan Januari sampai dengan Nopember 2013 dengan metode survey. Hasil penelitian menunjukkan bahwa rata-rata ukuran panjang pertama kali matang kelamin $(\mathrm{Lm})$ udang jerbung di perairan Cilacap dan sekitarnya adalah pada panjang karapas 38,3 mm dan musim pemijahan berlangsung sepanjang tahun dengan puncaknya pada bulan Januari. Laju pertumbuhan udang jerbung jantan adalah 1,00 per tahun dan panjang karapas maksimum ( $\left.L_{\infty}\right)$ adalah $40,7 \mathrm{~mm}$ serta untuk udang betina didapatkan nilai $\mathrm{K}$ adalah 1,10 per tahun dan nilai $\mathrm{L} \infty$ adalah 54,2 mm. Laju kematian total (Z) udang jerbung jantan adalah 2,46 per tahun, laju kematian karena penangkapan $(F)$ dan laju kematian alami $(M)$ masing-masing 1,37 per tahun dan 1,09 per tahun. Untuk udang betina didapatkan nilai $Z$ adalah 1,69 per tahun, nilai $F$ dan nilai $M$ masingmasing 0,61 dan 1,08 per tahun. Laju pengusahaan (E) udang jerbung jantan adalah 0,56 per tahun dan nilai $E$ udang betina adalah 0,36 per tahun. Pola penambahan baru udang jerbung di perairan Cilacap berlansung sepanjang tahun dengan puncaknya pada bulan Maret dan April. Tingkat pemanfaatan udang jerbung jantan sudah berada dalam tahapan overfishing dan perlu dilakukan pengurangan jumlah upaya.
\end{abstract}

Kata Kunci: Dinamika populasi; udang jerbung; pemanfaatan; Cilacap

\section{ABSTRACT}

High market demand of banana prawn have consequence in fishing activities which is carried out continuously throughout the year, so that could be threaten of resources sustainability. Scientific advices on the population characteristic are required as an input to support fisheries management. The purpose of the study was to identify population characteristic of the banana prawn with survey method. Study on the population characteristic of banana prawn ( $P$. merguiensis de Man) was conducted in Cilacap and the surrounding waters based on data collected during, January 2013 to November 2013. Result showed that the size at first maturity $(\mathrm{Lm})$ of banana prawn was $38.3 \mathrm{~mm}$ in carapace length. The spawning season of banana prawn in Cilacap and the surrounding waters occures throughout the year with the peak in January. The growth parameters of male (K) was 1.0/ year with maximum carapace length (Lo) of $40.7 \mathrm{~mm}$ and $K$ for female was 1.10/year with maximum carapace length of 54,2 $\mathrm{mm}$. Instantaneous total mortality rate $(Z)$ and natural mortality rate $(M)$ of male were 2.46/year and 1.09/year, respectively. While fishing mortality $(F)$ and exploitation rate $(E)$ respectively were $1.37 /$ year and $0.56 /$ year. The total mortality $(Z)$ and natural mortality $(M)$ of female 
respectively were 1.69/year and 1.08/year. Fishing mortality $(F)$ and exploitation rate $(E)$ were $0.61 /$ year and 0.36/year. The recruitment pattern of banana prawn in Cilacap and surrounding waters occures throughout the year with two peaks in March and April. The exploitation rate of male of banana prawn fisheries in Cilacap waters was high. It was, therefore, recommended that fishing effort of the banana prawn in that waters should be reduced in the next year.

\section{Keywords: Population dynamic; banana prawn; exploitation; Cilacap}

\section{PENDAHULUAN}

Udang jerbung merupakan salah satu udang ekonomis penting di perairan Cilacap dan sekitarnya. Kontribusi produksi udang jerbung di perairan ini sekitar $30-50 \%$ dari sisi produksi dan $50-70 \%$ dari sisi nilai produksi udang Penaeid (Suman, 2004; Kembaren et al., 2013). Pemanfaatan sumber daya udang di perairan Cilacap sudah lama dilakukan, tetapi secara komersial baru dimulai pada tahun 1966, dengan mulai berkembangnya perikanan trawl untuk menangkap udang di perairan ini (Naamin,1972). Sejak saat itu perkembangan pemanfaatan udang di perairan ini sangat intensif dan meningkat setiap tahun akibat bertambahnya armada penangkapan dan angkatan kerja (Van Zalinge \& Naamin, 1975; Naamin, 1978; Kembaren et al., 2013).

Walaupun sumber daya udang termasuk sumber daya yang dapat pulih (renewable resources) tetapi penangkapan yang terus meningkat tanpa adanya pembatasan akan menyebabkan habisnya sumber daya tersebut. Mengingat tingginya intensitas penangkapan udang jerbung yang mencapai 3567 unit alat tangkap trammel net, yang dilakukan setiap hari sepanjang tahun, maka dikhawatirkan kondisi pemanfaatannya akan mengancam kelestarian dan keberlanjutan pemanfaatan sumber daya udang jerbung di perairan Cilacap dan sekitarnya. Hal ini telah terindikasi dengan terjadinya penurunan CPUE akhir-akhir ini, padahal di lain pihak terjadinya kenaikan jumlah upaya penangkapan (Kembaren et al., 2013; BPPL, 2015).

Melihat fenomena tersebut maka di perairan Cilacap dan sekitarnya harus dilakukan upaya-upaya pengelolaan pemanfaatan sumber daya udang jerbung yang lebih baik, sehingga sumber daya udang jerbung yang ada masih dapat menjadi modal bagi pemulihan (recovery) stok dalam kaitan pemanfaatannya secara berkelanjutan. Agar pemanfaatan sumber daya udang jerbung di perairan Cilacap dan sekitarnya dapat dilakukan secara berkelanjutan maka pengelolaannya harus didasarkan pada pengetahuan tentang aspek dinamika populasi. Tulisan ini akan membahas dinamika populasi udang jerbung di perairan Cilacap dan sekitarnya dan diharapkan dapat digunakan untuk tujuan pengelolaan serta dasar bagi pengkajian selanjutnya.

\section{BAHAN DAN METODE}

Penelitian ini dilakukan dari Januari sampai dengan Nopember 2013 di perairan Cilacap dan sekitarnya (Gambar 1). Penelitian dilakukan dengan pengamatan sekali seminggu di pusat pendaratan udang di Cilacap dan sekitarnya dengan jumlah sampel minimal 100 ekor per bulan. Pengamatan biometrik udang hasil tangkapan trammel net dilakukan secara acak, sehingga struktur ukuran populasi dapat terwakili. Pengukuran yang dilakukan terhadap contoh meliputi pengukuran panjang karapas, jenis kelamin dan kematangan gonad. Penentuan jenis kelamin udang dilakukan dengan mengamati organ reproduksinya yaitu petasma yang terdapat diantara pasangan kaki renang pertama pada udang jantan dan thelycum yang terdapat pada pasangan kaki jalan kelima pada udang betina. Tingkat kematangan gonad ditentukan secara morfologi sesuai dengan kriteria indeks kematangan kelamin yang dikemukanan oleh Naamin (1984) yaitu (1) dara (quiescent/undeveloped), (2) berkembang (developed), (3) hampir matang (early mature), (4) matang (ripe) dan (5) salin (spent). Panjang karapas diukur dengan menggunakan jangka sorong (tingkat ketelitian 0,01 mm). Data panjang karapas yang diperoleh kemudian ditabulasikan dalam bentuk tabel distribusi frekuensi panjang karapas dengan interval $2 \mathrm{~mm}$. Data frekuensi panjang karapas tersebut selanjutnya digunakan untuk mengestimasi parameter populasi udang jerbung. 


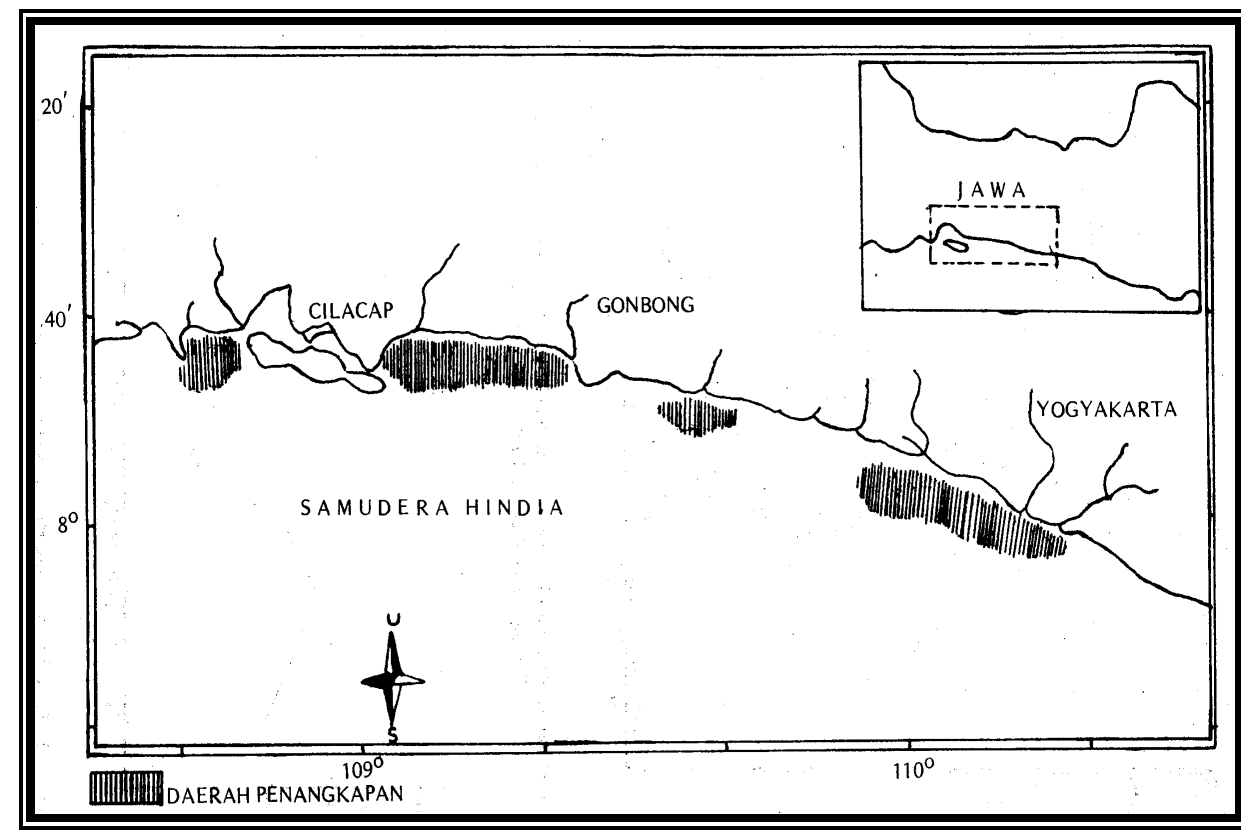

Gambar 1. Daerah penangkapan udang jerbung (P. merguiensis de Man) di perairan Cilacap dan sekitarnya. Figure 1. Fishing ground of banana prawn (P. merguiensis de Man) in Cilacap and surrounding waters.

Analisis rata-rata ukuran matang kelamin pertama kali memijah (Lm) udang jerbung mengunakan metode Spearman-Karber (Udupa, 1986). Laju pertumbuhan udang dianalisis menggunakan model pertumbuhan von Bertalanffy (Sparre \& Venema, 1992) dengan persamaan sebagai berikut:

$$
L t=L_{\infty}\left(1-e^{-K(t-t 0)}\right)
$$

Penentuan panjang karapas asimtotik (Lo) dan koefisien pertumbuhan $(\mathrm{K})$ diduga menggunakan program Electronic Length Frequency Analysis (ELEFAN) yang dikemas dalam perangkat lunak FISAT II (Gayanilo et al., 2005). Laju mortalitas alamiah (M) diduga dengan persamaan empiris Pauly (1983) yang menggunakan data rerata suhu permukaan perairan tahunan $(\mathrm{T})$ yaitu $29^{\circ} \mathrm{C}$ sebagai berikut:

$$
\begin{aligned}
\log (M)= & -0,0066-0,279 \log C L \infty+0,6543 \log K+ \\
& 0,4634 \log T \ldots \ldots \ldots \ldots \ldots \ldots \ldots \ldots \ldots \ldots \ldots . .2)
\end{aligned}
$$

Pendugaan mortalitas total (Z) dilakukan dengan metode kurva konversi hasil tangkapan dengan panjang (length converted catch curve) pada paket program FISAT II (Pauly, 1983; Gayalino et.al., 2005). Mortalitas penangkapan (F) dan laju eksploitasi (E) dihitung dengan rumus (Pauly, 1983): $Z=F+M$ dan $E=F / Z$
Pola penambahan baru dianalisis dengan program FISAT II (Gayanilo et al., 2005)

\section{HASIL DAN BAHASAN Hasil}

\section{Rata-rata Ukuran Pertama Kali Matang Kelamin dan Musim Pemijahan}

Selama penelitian ini diamati udang jantan sebanyak 1.100 ekor dan udang betina betina sebanyak 1.378 ekor. Selanjutnya dengan menggunakan metode Spearman-Karber (Udupa, 1986) didapatkan rata-rata udang jerbung pertama kali matang kelamin (Lm) pada panjang karapas 38,3 $\mathrm{mm}$. Untuk mengetahui musim pemijahan udang di suatu perairan diteliti melalui pengamatan terhadap penyebaran densitas telur atau dapat pula melalui pengamatan terhadap kematangan gonad udang betina di perairan tersebut (Martosubroto,1978). Udang jerbung betina yang didapatkan terdiri dari yang belum matang gonad sebanyak 1089 ekor (79\%) dan yang matang gonad sebanayak 289 ekor ( $21 \%$ ). Pada Tabel 1 diterakan persentase udang jerbung betina yang berada dalam tingkatan matang kelamin di perairan Cilacap dan sekitarnya. Dari Tabel 1 tersebut terlihat bahwa udang jerbung melakukan pemijahan sepanjang tahun dengan puncaknya pada Januari. 
Tabel 1. Sebaran frekuensi (\%) udang jerbung (P. merguiensis de Man) berdasarkan tingkat kematangan gonad di perairan Cilacap dan sekitarnya

Table 1. Frequency distribution (\%) of banana prawn (P. merguiensis de Man) base on gonad maturity in Cilacap and surrounding waters

\begin{tabular}{ccc}
\hline Bulan (Month) & \multicolumn{2}{c}{ Tingkat kematangan (Maturity Stage) } \\
& Matang (Mature) & Belum Matang (Immature) \\
\hline Januari & 33 & 67 \\
Pebruari & 29 & 71 \\
Maret & 13 & 87 \\
April & 16 & 84 \\
Mei & 11 & 89 \\
Juni & 26 & 74 \\
Juli & 15 & 85 \\
Agustus & 24 & 76 \\
September & 17 & 83 \\
Oktober & 21 & 79 \\
Nopember & 27 & 73 \\
\hline
\end{tabular}

\section{Parameter Pertumbuhan dan Laju Kematian}

Dengan merunut data frekuensi panjang karapas dari bulan ke bulan diperoleh laju pertumbuahn (K) udang jerbung jantan di perairan Cilacap dan sekitarnya 1,01 per tahun dan panjang karapas maksimum $\left(\mathrm{L}_{\infty}\right)$ sebesar $40,7 \mathrm{~mm}$, sedangkan untuk udang jerbung betina nilali laju pertumbuhannya $(K)$ adalah 1,10 per tahun dan panjang karapas maksimum $\left(\mathrm{L}_{\infty}\right)$ adalah 54,2 $\mathrm{mm}$. Dengan demikian persamaan pertumbuhuan von Bertalanffy untuk udang jerbung di perairan Cilacap dan sekitarnya adalah:

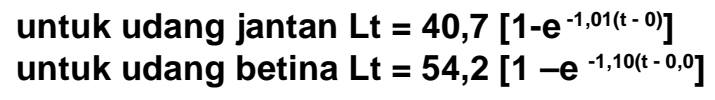

Selanjutnya dengan menggunakan parameter pertumbuhan udang jerbung yang telah dihitung $(\mathrm{K}=$ 1,01 per tahun, $\mathrm{L}_{\infty}=40,7 \mathrm{~mm}$ untuk udang jantan serta $\mathrm{K}=1,10$ per tahun dan $\mathrm{L}_{\infty}=54,2 \mathrm{~mm}$ untuk udang betina) sebagai bahan masukan untuk membuat kurva hasil tangkap, diperoleh nilai dugaan $Z$ untuk udang jerbung jantan sebagai 2,46 per tahun dan 1,69 per tahun untuk udang betina. Nilai dugaan laju kematian alamiah (M) dihitung dengan menggunakan persamaan Pauly (1983) dan diperoleh nilai $\mathrm{M}$ untuk udang jerbung jantan sebesar 1,09 per tahun dan untuk udang betina sebesar 1,08 per tahun. Nilai dugaan laju kematian karena penangkapan $(F)$ dihitung dan diperoleh hasil sebesar 1,37 per tahun untuk udang jerbung jantan serta 0,61 per tahun untuk udang jerbung betina.

\section{Laju Eksploitasi dan Pola Penambahan Baru}

Dengan menggunakan nilai $F$ yang merupakan gambaran tekanan penangkapan dan nilai $Z$ yang merupakan gambaran kematian total karena penangkapan dan faktor alam maka diperoleh nilai laju pengusahaan (E) udang jerbung jantan sebesar 0,56 per tahun dan untuk udang betina sebagai 0,36 per tahun. Nilai $E$ ini menggambarkan tingkat pemanfaatan udang jerbung jantan sudah melebihi potensi lestari.

Analisis pola penambahan baru udang jerbung menunjukkan ada dua modus yang tumpang tindih dalam satu tahun, yang diduga berkaitan dengan perilaku udang jerbung yang memijah secara parsial (partial spawner). Udang jerbung terlihat melakukan pemijahan sepanjang tahun dengan dua puncak yaitu pada bulan Maret dan April.

\section{Bahasan}

Ukuran udang pada saat kematangan gonad penting artinya dalam pengelolaan perikanan mengingat bahwa eksploitasi harus membiarkan sejumlah tertentu induk-induk ikan (udang) yang mempunyai ukuran sama atau lebih dari ukuran tersebut pada saat mencapai kematangan (Sudjastani, 1974). Pada umumnya udang betina mengalami kematangan kelamin pada ukuran yang lebih besar dari pada udang jantan (Martosubroto, 1978). Dibandingkan dengan udang jerbung dari periode penelitian sebelumnya di perairan Cilacap (Tabel 2), ternyata udang jerbung di perairan Cilacap dan sekitarnya masih relatif sama untuk rata-rata ukuran pertama kali matang gonad (panjang karapasnya 38,3 $\mathrm{mm}$ ). Fenomena ini mengindikasikan bahwa tekanan penangkapan udang jerbung perairan Cilacap sampai saat ini belum mempengaruhi proses pembaruan populasi. 
Tabel 2. Rata-rata ukuran panjang pertama kali matang gonad (Lm) udang jerbung (P. merguiensis de Man, 1888) pada berbagai perairan

Table 2. The legth at first maturity ( $\mathrm{Lm})$ of banana prawn (P. merguiensis de Man, 1888) in some waters area

\begin{tabular}{ccc}
\hline Perairan (Waters) & Lm (CL-mm) & Sumber (Source) \\
\hline Demak & 39,70 & Suman (1994) \\
Tanjung Krawang & 26,0 & Martosubroto (1978) \\
Teluk Bintuni & 33,87 & Sumiono (1983) \\
Cilacap & 39,59 & Adisusilo (1983) \\
Panimbang & 40,70 & Suman (1988) \\
Kupang dan Belu & 41,80 & Suman (1991) \\
\hline
\end{tabular}

(Sumber: Suman \& Subani, 1994)

Analisis lebih lanjut menunjukkan nilai $\mathrm{Lm}$ di perairan Cilacap cenderung lebih rendah dibandingkan perairan Demak, Panimbang, Kupang dan Belu, tetapi lebih tinggi bila dibandingkan dengan di perairan Tanjung Krawang dan Teluk Bintuni (Tabel 2). Adanya perbedaan rata-rata ukuran pertama kali matang $(\mathrm{Lm})$ pada berbagai perairan dipengaruhi oleh ketersediaan makanan dan kondisi lingkungan lainnya, seperti suhu dan salinitas. Menurut Udupa (1986), ukuran pada saat kematangan bervariasi diantara spesies dan di dalam spesies yang sama.

Kepentingan dari pengetahuan musim pemijahan dalam prinsip pemanfaatan sumber daya udang jerbung secara berkelanjutan adalah untuk mengetahui kapan waktunya diadakan penutupan daerah dan musim penangkapan dalam rangka memberi kesempatan pada induk-induk udang untuk melakukan pemijahan. Musim pemijahan udang jerbung di perairan Cilacap berlangsung sepanjang tahun dengan puncaknya pada Januari. Hal yang sama ditemukan di berbagai perairan yang menunjukkan musim pemijahan berlangsung sepanjang tahun tetapi puncak musimnya berbeda (Tabel 3).

Untuk menjaga kelestarian sumber daya udang jerbung, maka perlu diatur pola penangkapan udang jerbung di perairan Cilacap dan sekitarnya, sehingga tersedia waktu yang tenang bagi udang untuk melakukan pemijahan. Dalam kaitan tersebut, penutupan musim penangkapan udang jerbung di perairan Cilacap harus dilakukan minimal pada bulan Januari setiap tahunnya. Dengan demikian pada bulan Januari tersebut merupakan bulan yang dikondisikan agar udang jerbung dapat melakukan pembaruan populasi secara maksimal.

Pada dasarnya program ELEFAN digunakan untuk menginterpretasikan data frekuensi panjang karapas dengan cara melacak pergeseran modus sebaran frekuensi panjang karapas dalam suatu urutan waktu (time series) yang dicocokkan dengan kurva von Bertalanffy. Kurva yang melalui modus paling banyak akan menggambarkan pola pertumbuhan (Sparre \& Venema,1992). Nilai K udang jerbung betina juga terlihat lebih besar dari nilai K udang jantan dan hal ini tercermin juga dalam hasil tangkapan, diamana ukuran udang jerbung betina didapatkan selalu lebih besar dari udang jantan. Dall et al. (1990) menyatakan bahwa pertumbuhan udang betina selalu lebih cepat dari udang jantan dan biasanya pada umur yang sama selalu ditemui udang betina lebih besar dari udang jantan. Nilai $\mathrm{K}$ udang jerbung yang lebih besar dari satu juga menunjukkan bahwa udang jerbung ini mempunyai pertumbuhan yang cepat (Gulland,1983; Naamin, 1984). Semakin rendah nilai K maka akan semakin lama suatu spesies mencapai nilai $L_{\infty}$, begitu juga sebaliknya (Sparre \& Venema, 1992). Pada Tabel 4 disajikan nilai $K$ dan $L_{\infty}$ udang jerbung dari berbagai perairan.

Tabel 3. Puncak musim pemijahan udang jerbung ( $P$. merguiensis de Man) pada berbagai perairan Table 3. The peak of spawning season of banana prawn (P. merguiensis de Man) in some waters area

\begin{tabular}{ccc}
\hline Perairan (Waters) & $\begin{array}{c}\text { Puncak Musim } \\
\text { (Peak Season) }\end{array}$ & Sumber (Source) \\
\hline Pantai Utara Jawa Tengah & Oktober dan Nopember & Naamin, 1971 \\
Tanjung Krawang & Maret dan Desember & Martosubroto (1978) \\
Panimbang & September & Suman (1989) \\
Pantai Utara Jawa Barat & Maret dan Mei & Suman (1991) \\
\hline
\end{tabular}

(Sumber: Suman dan Subani, 1994) 
Tabel 4. Laju pertumbuhan $(\mathrm{K})$ dan panjang karapas maksimum $\left(\mathrm{L}_{\infty}\right)$ udang jerbung $(P$. merguiensis de Man) pada berbagai perairan

Table 4. The growth rate $(K)$ and maximum carapace length $\left(\mathrm{L}_{\infty}\right)$ of banana prawn (P. merguiensis de Man) in some waters area

\begin{tabular}{|c|c|c|}
\hline Perairan (Waters) & $\mathrm{K}$ (per tahun) Loo (mm) & Sumber (Source) \\
\hline Arafura & 50,2 & Naamin, 1984 \\
\hline Panimbang & 51,0 & Suman \& Sumiono (1989) \\
\hline Demak & 62,5 & Suman (1994) \\
\hline P. Utara Jawa Barat & 52,1 & Suman (1991) \\
\hline
\end{tabular}
(Sumber: Suman dan Subani, 1994)

Pada Tabel 4 tersebut terlihat parameter pertumbuhan ( $K$ dan $L_{\infty}$ ) berbeda pada berbagai perairan. Hal ini kemungkinan disebabkan oleh pengaruh kondisi lingkungan yang berbeda pada masing-masing perairan tersebut (Przybylski, 1996; Tsoumani, 2006). Kondisi lingkungan tersebut meliputi ketersediaan makanan, suhu perairan, oksigen terlarut, ukuran ikan dan kematangan gonad (Jamal et al., 2011). Knaepkens et al. (2002) dan Effendie (2002) menyatakan perbedaan nilai $K$ dan $L_{\infty}$ disebabkan oleh faktor internal/intrinsik dan faktor eksternal. Faktor internal yang berpengaruh tersebut meliputi keturunan, parasit dan penyakit, sementara faktor eksternal berupa suhu dan ketersediaan makanan.

Pada perikanan udang jerbung yang telah berkembang di perairan Cilacap, laju kematian total (Z) merupakan kombinasi dari laju kematian alamiah (M) dan laju kematian karena penangkapan (F) (Sparre \& Venema, 1992). Nilai M udang jerbung jantan di perairan Cilacap terlihat lebih lebih kecil dibanding nilai $\mathrm{F}$-nya, sementara nilai $\mathrm{M}$ udang jerbung betina lebih besar dibanding nilai F-nya. Hal ini menunjukkan bahwa sebagian besar udang jerbung jantan di perairan Cilacap mati karena penangkapan, sebaliknya pada kematian udang betina sebagian besar dikarenakan faktor alamiah. Besarnya pengaruh faktor alamiah terhadap laju kematian udang betina tersebut diduga karena sifat yang udang betina yang lebih cepat tumbuh dibanding udang jantan sehingga lebih rentan untuk dimangsa predator. Selain itu udang betina juga harus melakukan migrasi ke perairan laut dalam untuk memijah dan hal ini mengakibatkan peningkatan laju kematian karena harus melakukan adaptasi pada lingkungan baru yang berbeda dari habitat aslinya (Naamin, 1984)

Laju eksploitasi udang jebung jantan dan betina di perairan Cilacap secara berturut-turut adalah 0,36 per tahun dan 0,56 per tahun. Jika dibandingkan dengan kriteria dari Pauly et al. (1984) yang menyatakan bahwa laju eksploitasi optimal adalah 0,5 , maka laju eksploitasi udang jerbung jantan telah melebihi nilai laju optimal, sementara untuk udang jerbung betina masih dibawah nilai 0,5 . Hal tersebut menunjukkan bahwa tingkat pemanfaatan udang jerbung betina sudah berada pada tangkapan yang berlebih (overfishing), sedangkan udang jantan masih dalam tahapan tangkap jenuh (fully-exploited). Agar sumber udang jerbung di perairan Cilacap dapat terjaga kelestariannya, maka harus dilakukan pengurangan upaya penangkapan sekitar $12 \%$ dari kondisi saat ini.

Secara umum, udang jerbung mengalami penambahan baru sepanjang tahun dengan puncaknya pada bulan Maret dan April. Hal ini menunjukkan bahwa pada periode tersebut terjadi peningkatan yang nyata pada populasi udang jerbung dibandingkan dengan populasi sebelumnya. Dengan melihat periode puncak penambahan baru tersebut, terlihat udang jerbung melakukan penambahan baru tertinggi pada musim peralihan dari musim hujan ke musim kemarau. Pada periode tersebut kondisi lingkungan perairan jernih dan suhu relatif dingin (BPPL, 2015), yang memacu udang jerbung untuk berkembang biak secara maksimal.

\section{KESIMPULAN}

Rata-rata ukuran pertama kali matang kelamin udang jerbung betina ( $P$. merguiensis de Man) di perairan Cilacap dan sekitarnya adalah pada panjang karapas 38,3 mm dan musim pemijahan berlangsung sepanjang tahun dengan puncaknya pada bulan Januari. Laju pertumbuhan dan kematian udang jerbung tergolong tinggi, oleh karena itu pengelolaannya harus dilakukan secara hati-hati dan cermat. Laju eksploitasi udang jerbung betina sudah melebihi potensi lestarinya, sementara untuk udang jantan masih dalam tahapan jenuh (fully-exploited). Pola penambahan baru terjadi sepanjang tahun dengan puncaknya pada Maret dan April. Agar kelestarian sumber daya udang jerbung di perairan Cilacap dan sekitarnya dapat terjamin, harus dilakukan pembatasan ukuran udang jerbung yang terkecil yang boleh ditangkap pada panjang karapas $38,3 \mathrm{~mm}$, 
pentupan musim penangkapan pada bulan Januari serta pengurangan upaya sekitar $12 \%$ dari kondisi saat ini.

\section{PERSANTUNAN}

Tulisan ini merupakan bagian dari program enumerasi tahun anggaran 2013 pada Balai Penelitian Perikanan Laut Jakarta.

\section{DAFTAR PUSTAKA}

BPPL (2015). Penelitian karakteristik biologi perikanan, habitat sumber daya dan potensi produksi sumber daya ikan di WPP 573 (Samudera Hundia Selatan Jawa dan Nusa Tenggara). Laporan Akhir. Balai Penelitian Perikanan Laut, Pusat Penelitian dan Pengembangan Perikanan, Badan Penelitian dan Pengembangan Kelautan dan Perikanan.

Dall, W., Hill, B.J., Rothlisberg, P.C., \& Staples, D.J. (1990). The biology of the Penaeidae (p. 489). In Balxter, J.H.S and A.J. Southward (eds): Marine Biology Vol.27, Academic Press. London, San Diego, New York, Boston, Sydney, Tokyo, Toronto.

Effendie, M.I. (2002). Biologi perikanan, Yayasan Pustaka Nusatama (p.163), Yogyakarta.

Gayanilo, F. C. Jr., Sparre, P., \& Pauly, D. (2005). FAO ICLARM Stock Assessment Tools II (FiSAT II). Revised version. User's guide. FAO Computerized Information Series (Fisheries). No. 8, Revised version. FAO Rome. 168p.

Gulland, J.A. (1983). Fish stock assessment (p. 233). A manual of basic methods. John Wiley \& Sons, Chicester.

Jamal, M., Muhammad, F.A.S, John, H., \& Budi, W. (2011). Pemanfaatan data biologi ikan cakalang (Katsuwonis pelamis) dalam rangka pengelolaan perikanan bertanggung jawab di perairan Teluk Bone. Jurnal Natur Indonesia, 14 (1), 107-113.

Kembaren, D.D., Nurdin, E., Wedjatmiko, Ernawati, T., Lestari, P., Damora, A., Ramadhani, R., Rijal, M., Setiawan, R., Putrie, L. M., \& Johardi, E. (2013). Penelitian status dan optimasi pemanfaatan sumber daya udang Penaeid dan krustasea lain dalam mendukung industrialisasi perikanan di Samudera Hindia Barat Sumatera (WPP 572), Samudera Hindia Selatan Jawa dan Nusa Tenggara (WPP 573) serta di Teluk Cederawasih dan Samudera Pasifik (WPP 717).
Laporan Akhir. Balai Penelitian Perikanan Laut, Pusat Penelitian Pengelolaan Perikanan dan Konservasi Sumber Daya Ikan, Badan Penelitian dan Pengembangan Kelautan dan Perikanan.

Martosubroto, P. (1978). Musim pemijahan dan pertumbuhan udang jerbung (Penaeus merguiensis de Man) dan udang dogol (Metapenaeus ensis de Haan) di perairan Tanjung Krawang. Prosiding Seminar Ke II Perikanan Udang. 7-20 hal.

Knaepkens, G., Knapen, D, Bervoets, L., Hanfling, B., Verheyen, E., \& Eens, M. (2002). Genetic diversity and condition factor: a significant relationship in Flemish but not in German populations of the the European bullhead (Cottus gobio L.). Heredity, 89, 280-287.

Naamin, N. (1972). Perkembangan perikanan udang di perairan Cilacap dan Pangandaran. Laporan Penelitian Perikanan Laut. (1), 59 - 79.

Naamin, N. (1978). Perkembangan perikanan udang di Indonesia. Prosiding Seminar Ke II Perikanan Udang, 55-65 hal.

Naamin, N. (1984). Dinamika populasi udang jerbung (Penaeus merguiensis de Man) di perairan Arafura dan alternative pengelolaannya. Disertasi Doktor pada Fakultas Pasca Sarjana, IPB Bogor: 381 hal.

Pauly, D. (1983). Some Simple Methods for the Assessment of Tropical Fish Stocks. FAO Fisheries Technical Paper (254): 52p.

Pauly, D., Ingles, J., \& Neal, R. (1984). Application to shrimp stocks of objective methods for the estimation of growth, mortality and recruitment related parameters from length frequency data (ELEFAN I and II). In: Penaeid shrimp - their biology and management: 220-234. Fishing News Book Limited. Farnham-Surrey-England.

Przybylski, M. (1996). Variation in fish growth characteristics along a river course. Hydrobiology. 325, 39-46.

Sparre, P., \& Venema, S.C. (1992). Introduction to tropical fish stock assessment. Part I Manual. FAO Fish. Tech Pap. No. 306/1.

Sudjastani, T. (1974). Dinamika populasi ikan kembung di laut Jawa. Laporan Penelitian Perikanan Laut. 1, 30-64. 
Suman, A., \& Subani, W. (1994). Penelitian beberapa aspek biologi udang jerbung (Penaeus merguiensis de Haan) di perairan Demak, Jawa Tengah. Jurnal Penelitian Perikanan Laut. 91, 64 - 71.

Suman, A. (2004). Pola pemanfaatan sumber daya udang dogol (Metapenaeus ensis de Haan) di perairan Cilacap dan sekitarnya. Disertasi, Sekolah Pascasarjana IPB, Bogor: $163 \mathrm{hlm}$.

Tsoumani, M., Liaska, R., Mousaki, P., Kagalao, I., \& Leonardos, I. (2006). Length-weight relationship of an invasive cyprinid (Carassius gibelio) from 12 Greek Lake in relation to their trophic states. Journal Applied Ichtyologi, 22, 281-284.

Udupa, K.S. (1986). Statistical method of estimating the size at first maturity in fishes. Fishbyte 4 (2): 8-10. ICLARM, Metro Manila.

Van Zalinge, N.P. \& Naamin, N. (1975). The Cilacap based trawl fishery for shrimp along the south coast of Java. Laporan Penelitian Perikanan Laut. (2), 1-15. 